\title{
Textile Printing
}

\section{Its Power Requirements and Electric Drive}

\author{
BY CHARLES T. GUILDFORD \\ Member, A. I. E. E. \\ Westinghouse Electric \& Manufacturing Company, E. Pittsburgh, Pa.
}

\begin{abstract}
Review of the Subject.-Textile printing is the process of applying colored patterns and designs to all sorts of textile fabrics. The origin of the art dates back about 2000 years and credit for its discovery is given to both China and India. The present method of printing, known as cylinder or roller printing was invented and received its initial success about 1783-85.

There are five methods used in textile printing, namely hand block printing, perritone or machine block printing, stenciling, flat surface printing from engraved copper plates, and cylinder printing from engraved copper rollers.

Of the five, cylinder printing is the most modern and important. By this means almost any style of design on almost any fabric can be produced in from one to sixteen colors, and the output from such a machine compared to hand block printing is enormous. For example, the cylinder machine can readily print in $11 / 2$ minutes the same number of yards of cloth that would require 15 hours by the block method.
\end{abstract}

The machine in its simplest form, viz.: a one-color machine, consists of a print roll or hollow copper cylinder upon which the pattern to be printed is engraved, a cast iron cylinder, the surface of which serves as a backing for the cloth to be printed, the furnisher or roll which carries the color to the print roll, the cleaning doctor which removes the surplus color from the print roll, and the color box which holds the color. The rolls are suitably mounted in. bearings so that the print roll surface is in contact with the cylinder, the cloth passing between the print roll and the cylinder. Color is supplied from the color box by the furnisher to the print roll which imparts it to the cloth. After printing the cloth is passed over dryers to dry the fresh color.

The load on a printing machine consists of two parts, (a) constant load consisting of the dryers, guide roll and cloth conveyers, and (b) a variable load depending principally upon the class of goods to be printed, the length of and pressure used on the print rolls and the speed of the machine. The print roll pressure depends much upon the operator giving what in his estimation is the proper set for the rolls. This has been found to vary as much as 100 per cent for the same class of goods.

$A$ series of tests made on several machines each driven by a $d-c$. motor, in one plant printing cotton cloth 27 to 36 in. wide, gives the following results:

Speed Variation: On machines ranging from four to nine colors a maximum machine speed range on any one machine was 4.82 to 1 with a maximum and minimum production for all machines of 84 to $1 \frac{1}{4}$ yards per minute.

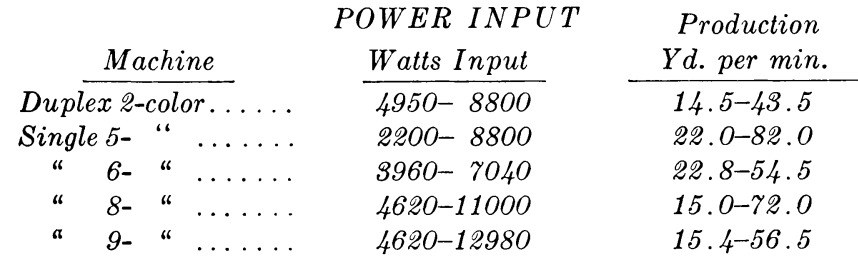

$\mathrm{T}$

EXTILE printing is the process of applying by various means colored patterns or designs to all sorts of textile fabrics, cotton, wool, silk, jute, linen and various mixtures of these and other fabrics.

The process is a form of dyeing and differs from it only in the fact that in dyeing the goods are colored
From a variety of tests in different plants it appears that no fixed rule can be given to cover power requirements of a machine of given size. Experience and tests in a given plant enable one sometimes to fix approximate ratings for these machines, running a given line of goods. For example, a large printing plant running silk goods has adopted the following ratings.

$\begin{array}{ccc}\text { Three-color machine } & 10 \mathrm{~h} . \mathrm{p} . \\ \text { Six " } & \text { " } & 15 \mathrm{~h} . \mathrm{p} . \\ \text { Eight " } & & 20 \mathrm{~h} . \mathrm{p} . \\ \text { Twelve " } & & 30 \mathrm{~h} . \mathrm{p} .\end{array}$

Another large printing plant running cotton goods has adopted the following:

$\begin{array}{lll}\text { Three-color machine } & 20 \mathrm{~h} . \mathrm{p} . \\ \text { Five " } & \text { " } & 27 \mathrm{~h} . \mathrm{p} . \\ \text { Six } & \text { " } & 35 \mathrm{~h} . \mathrm{p} .\end{array}$

There are three general methods of electric drive used on printing machines: (1) Direct-current motor with multi-voltage control. (2) Commutator-type a-c. motor. (3) Direct-current motor with field and armature control by resistance. The first is one which supplies a number of operating voltages for the motor to give the necessary speed changes and requires special generating equipment, together with additional lines to supply these voltages. The second is the straight series type commutating motor with brush-shifting device. The motor is operated from a constant-potential a-c. line and speed changes are obtained by shifting the brushes on the commutator.

The third is the standard d-c. type with speed control through resistance for both field and armature, and is operated automatically by push buttons or manually with face plate or drum controller.

The control for the d-c. motor consists of a series of magnetic contactors and rheostats either mounted complete on a panel or with rheostats combined in a single unit and separately mounted.

The operating push-buttor station usually has 5 buttons consisting of the "start," "stop," "jog" or "inching," "low speed," and "high speed." The jog or inching button is for the purpose of operating at low speed when setting the print rolls for correct registration. The start button is for automatically accelerating to the speed for which rheostats are set (this speed may be low or fullload speed of the motor, depending upon whether the slow or the fast button has been depressed), the slow button for the low speed to enable the operator to inspect the quality of printing, the fast button to bring the motor up to the highest speed at which the cloth can be printed and dried, and the stop button to stop the machine on any speed. Single stop buttons are in addition located at several convenient locations for stopping.

Dynamic braking is often desirable to bring the machine to a quick stop and is readily obtained with this control.

uniformly throughout, while in printing, the color is placed on part of the goods only in the form of a design. The basic coloring material used for both is the same, although any colors capable of being made into a viscous fluid can be used for printing, in which case the development of the color may be completed either by steaming or dyeing. 


\section{HISTORY}

Without attempting to go into the details of the history of the art, a few facts gleaned from authorities on the subject will give an idea of its origin and entrance into Europe where it received its greatest impetus and development.

The art of printing appears to have been discovered and practised independently and at different times by several countries. Letter press printing from engraved blocks of wood was practised in China nearly two thousand years ago. Printed cottons by the Hindoos were known and esteemed by the Romans in the early days of the empire and discoveries in the Egyptian tombs of fragments of cloth decorated with colored designs give evidence of a knowledge of some form of the art. The matter of priority seems to be an unsettled question, but it is generally conceded to lie between China and India. The Chinese were the first to use engraved blocks of wood for general printing and it is thought probable that the same idea would lead to the decoration of textiles. On the other hand, as the art was a flourishing commercial industry in India during the earliest centuries of the Christian era, it is possible that the art originated in this country. In any case, the source of European textile printing is traced to India.

About the latter part of the seventeenth century, the French, from their possessions in India, obtained a knowledge of the art and it is probable that they were the first to practise calico printing in Europe. From there it rapidly became known in Germany, Holland and England, and later spread to other countries. At the present time it is practised in all parts of the civilized world, and advance in the art in the last two centuries has been so great, and the output so large, as to be many. times that of the eighteen centuries preceding.

The present method of printing, known as cylinder or roller printing, is the product of the invention generally credited to Belle, a Scotchman. Patents were taken out by him in 1783, and from 1785 , when it received its initial success, to the present time, it has been the method most largely used.

\section{Methods of PRInting}

There are five methods used in textile printing, viz., hand block printing, Perritone or machine block printing, stenciling, flat press printing from engraved copper plates, and cylinder printing from engraved copper rollers.

Of the five, cylinder printing is the most modern and most important.

Each method has its advantages and no one can replace the other without sacrificing some desirable quality of work. Block printing is the oldest and generally considered the most artistic and after cylinder printing, the most important. In block printing, the design is cut in relief in a block of close-grained wood, and the color is applied to the raised parts and the block is stamped by hand or by machine upon the cloth to be printed; while in cylinder printing, the design is engraved on a copper roller and the color is applied to the incisions and the impression made by pressing the color into the cloth by revolving the roll and pressing the cloth against its surface, both operations being done by the machine. By this means nearly any style of design on almost any fabric can be produced in from one to sixteen colors and the output from such a machine compared with hand block printing is enormous, running as high as 18,000 yards of cloth in one color and 9000 yards in twelve colors per machine in a working day.

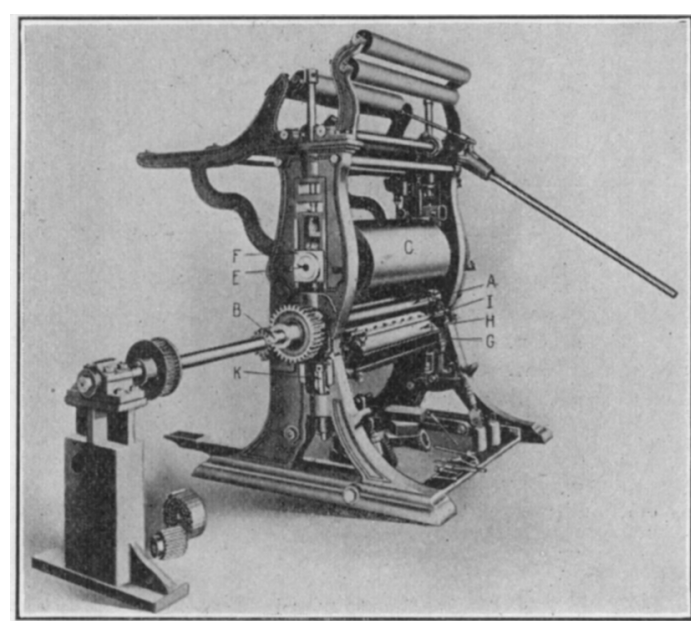

Fig. 1-One-Color Machine

$A$ Print roll.

$B$ Print roll mandrel.

$C$ Impression cylinder.

$E$ Cylinder shaft.

$F$ Cylinder bearing box.

$G$ Color box.

$H$ Color furnisher roll.

$I$ Cleaning doctor.

$K$ Print roll pressure screw.

Courtesy Rice, Barton \& Fales Machine \& Iron Co., Worcester, Mass.

To quote an apt comparison given by Mr. Robert Roech, in a paper read before the National Association of Cotton Manufacturers:

To state briefly, block printing was done on precisely the same principle as the stamp and pad in common use today, but on a larger scale. Blocks were usually ten to twelve inches square, so that with a block of 12 inches square it would require 450 impressions to print a piece 50 yards long and one yard wide, and if it should happen to be a four-color pattern it would then mean 1800 impressions. It would take a very smart printer to print two impression per minute, making allowance for changes, etc. This would mean 15 hours for 1800 impressions, whereas a cylinder printing machine could readily do the same number of yards in one and a half minutes. This gives an idea of the immense gain in product since the introduction of the cylinder printing machine, and for many classes of fine work the difference in quality is almost as marked.

\section{CyLinder PRinting Machine}

The modern cylinder printing machine is illustrated in Figs. 1 and 2.

Fig. 1 shows a one-color machine, which, as the name 
implies, prints the design in but one color and is therefore the simplest of this class of machines. Fig. 2 gives the end view of a two-color machine, and is here shown with Fig. 1 to illustrate more clearly the relation of the print roll to the cylinder. Referring to both figures, the machine consists of the following working parts:

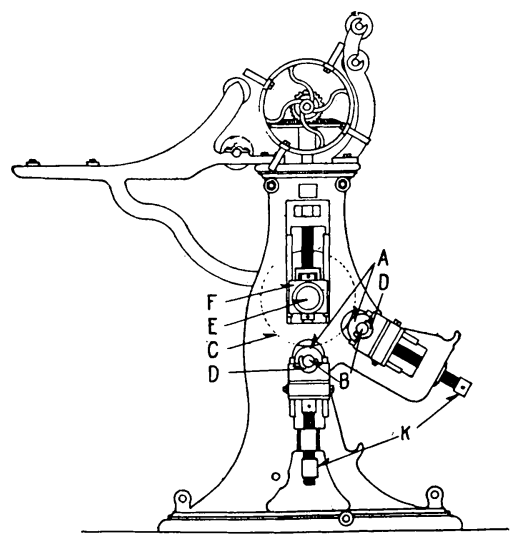

Fig. 2-Two-Color Machine

A Print rolls.

$B$ Print roll mandrel.

C: Impression cylinder.

I) Mandrel bearings.

E. Cylinder shaft.

$F$ Cylinder bearing box.

$K$ Print roll pressure screws.

Courtesy Rice, Barton \& Fales Machine \& Iron Co., Worcester, Mass.

Print roll $A$-this is a hollow copper cylinder engraved with the pattern to be printed and is mounted on a steel shaft $B$, called the mandrel, which has its bearings $D$ at each end.

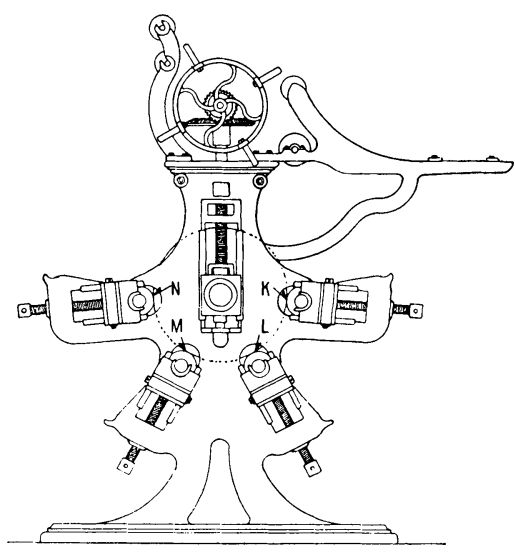

Fig. 3-Four-Color Machine

$K, L, M, N$, print rolls.

Courtesy Rice, Barton \& Fales Machine \& Iron Co., Worcester, Mass.

Cylinder $C$, a cast iron cylinder mounted on a steel shaft $E$ which runs in adjustable bearing boxes $F$ at each end. This cylinder furnishes the surface backing for the cloth to pass over while being printed and it is against this cloth on the cylinder that the print roll $A$ is pressed by screws $K$.

Furnisher $H$. This is a wooden or brush roll, mounted on a shaft with bearings at each end, which runs partly immersed in the color contained in the color box $G$ and operates within $1 / 16$ in. of the print roll.

Cleaning doctor. This is a sharp-edged metal blade which rests upon and behind the print roll about midway between the contact with the cylinder and the furnisher. Its function is to scrape off the superfluous color from the smooth parts of the print roll, leaving only the color in the lines of the engraving.

Lint doctor. This is a small blade mounted on the opposite side of the roll from the cleaning doctor and its function is to catch the loose filaments and nap from the cloth which stick on the print rolls. It is used only where goods have a tendency to shed lint.

Lapping. In order to impart to the cylinder the elasticity necessary to obtain a full impression of the pattern, the cylinder is wrapped with several thicknesses of special fabric called lapping.

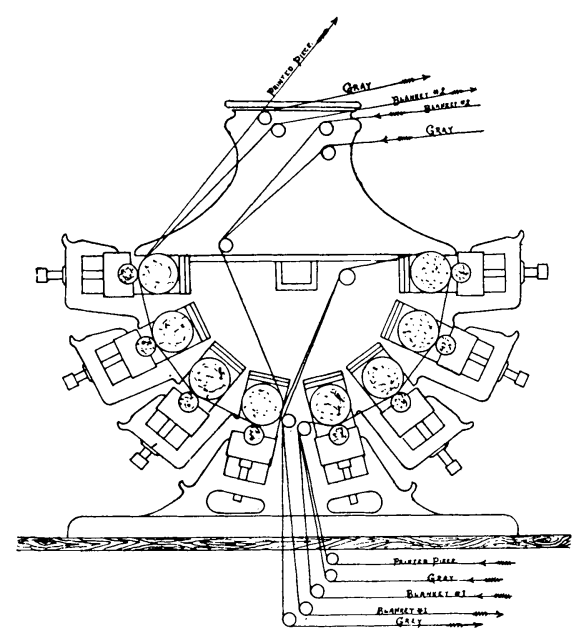

Fici. 4-Eight-Color Duplex Machine

Courtesy Rice, Barton \& Fales Machine \& Iron Co., Worcester, Mass.

Blanket. In order to give additional spring to the surface against which the print roll works, an endless woolen or rubber blanket circulates around the cylinder next to the lapping. See Figs. 4 and 5.

Back gray. This is a cloth which is run over the cylinder between the blanket and the cloth to be printed and its function is to absorb the color which comes through the printed cloth, thus preventing blurring of the printed cloth. See Figs. 4 and 5.

The above constitute the principal working elements of the machine. Other parts, such as the supporting frame, driving gears, cloth rolls, adjusting screws, etc., are contributory to revolving the print roll, furnishing the color therefor and passing the cloth over the cylinder to receive the printed design.

A two-color machine, Fig. 2, is made by adding to the one-color machine a second print roll with its color pan, furnisher and doctor. The surface of this second roll has engraved on it that part of the complete design which is to be printed in the second color, and the roll is so adjusted on the cylinder as to match and complete the counter part of the design printed from the 
first roll. In like manner a four-color machine is made by assembling four print rolls $K, L, M$ and $N$, as shown in Fig. 3. All other parts of the machine remain essentially the same, except that the supporting frame is made heavier and the necessary bearings and adjusting screws for the additional print rolls with their auxiliaries are added.

\section{Setting the Machine}

Before attempting to print even a sample of cloth, each of the print rolls of the machine is adjusted so as to give very nearly the correct registering of the design, one with the other. Two settings are necessary: First, longitudinally. This is accomplished by shifting each roll so that the index line of each cut around the circumference of the roll near the end is in the same vertical plane; this being determined by use of a small square placed on the surface and squaring successively each print roll from the cylinder. Second, circumferentially. This is accomplished by revolving each print

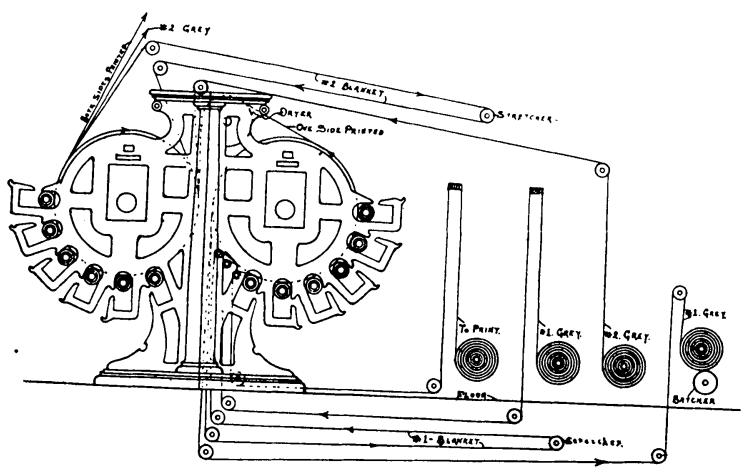

Fig. 5-Twelve-Color Double-Cylinder Duplex Machine Courtesy Rice, Barton \& Fales Machine \& Iron Co., Worcester, Mass.

roll so that the index point (marked on the roll) comes into register on the cylinder; this being determined by the use of a tape placed around the cylinder and having distance marked on it equal to the circumference of each print roll.

After these adjustments are made, the index points are filled with color and a small piece of cloth stuck to the gray is run slowly through the machine. The registration is printed on this cloth and if not correct, further adjustments are made and the cloth run through again. This is repeated until the registration is nearly correct. After this a quantity of cloth is run through the machine at lowest speed during which the final adjustment for registration of the complete design is made.

\section{RUNNING THE MaChINE}

After setting the machine, the goods are then run through at full speed, which varies with the class of goods and the number of colors being printed, $e . g$., on some cotton goods this may range from 40 to 80 yards per minute. As the cloth comes from the machine it is passed through hot air dryers, or over steam drying cans to dry the fresh colors, and this rate of drying determines in a measure the speed at which the cloth may be printed. Also inspection of the cloth requires a slowing down from full speed at intervals.

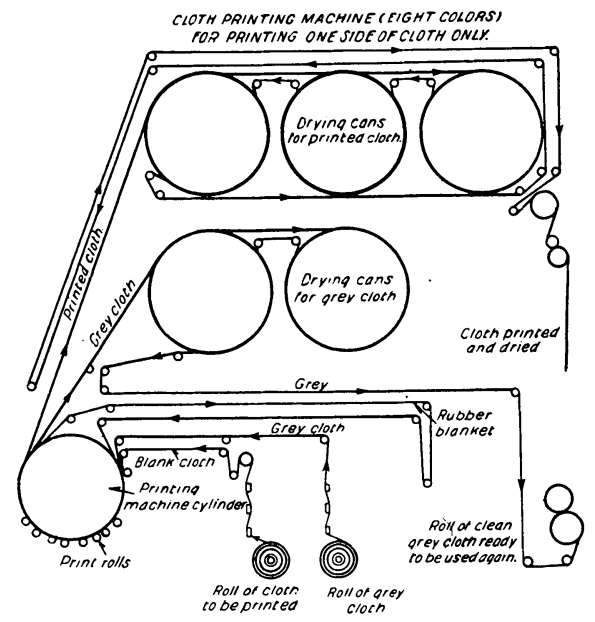

Fig. 6-Diagram Showing Travel of Print Cloth, Gray Cloth and Blanket during Printing and Drying Process On a machine printing on one side only.

\section{LOAD}

The load of a printing machine unit is madelup of two parts: (a) A constant load consisting of the dryers for the printed cloth, the delivery mechanism for the

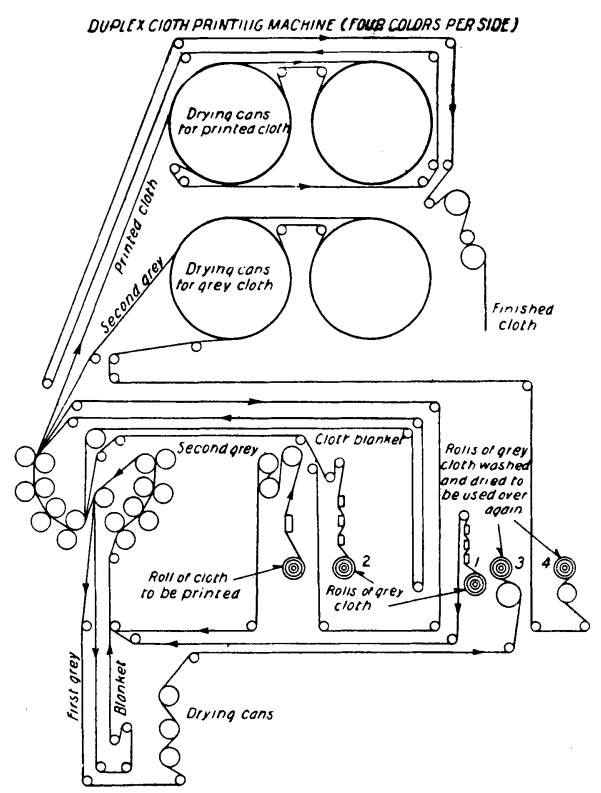

Fig. 7-Diagram Showing Travel of Print Cloth, Gray Cloth and Blanket during Printing and Drying Process On a machine printing on both sides of the cloth or "duplex" machine.

cloth, grays and blankets to and from the machine and dryers, the dryer blanket washer (if used) and oscillation of doctors. (b) A variable load depending on the following: 
1. Kind of goods being printed.

2. Length of, and pressure used on print rolls.

3. Speed of the machine.

4. Length of, and pressure used on color doctor.

5. Diameter of roll of cloth to be printed being fed to the machine and the weight applied to the brake wheel on the same.

6. Diameter of roll of grays and weight applied to the brake wheel on same.

7. Bearing friction of cylinder.

Items 4 to 7 inclusive may be considered negligible when compared with the total power requirements. Items 1,2 and 3 are the important items to be considered, and of these, item 2 is most important. The pressure on the cylinder makes up the larger part of the load and while the amount of this pressure or set of the print rolls depends upon and should be determined by the class of goods being run, it is in many cases determined by the operator, and as operators differ in their ideas as to how much set gives the best results, this item is not easily estimated. It depends entirely upon the human element and has been found to vary 100 per cent on similar work. Apparently there is no rule for the amount of this set, nor any means used to indicate it. Where a machine is driven by an electric motor the amperes for a given speed would indicate very closely the relative set. A large ammeter then placed where the operator and foreman could easily read it would be a means of determining and always running with the right set for the same goods.

Following are a series of tests made on several sizes of machines, showing speed variations and loads under normal operating conditions. The tests were made with d-c. motors with hand control.

TESTS

1. This series of five tests made on different machines shows the production and speed ranges during normal operation. It will be noted that the production ranged from 14.5 to 82 yards per minute, while the extreme speed range was 4.82 to 1 .

\begin{tabular}{|c|c|c|c|c|c|c|}
\hline \multirow[b]{2}{*}{ Colors } & \multirow{2}{*}{$\begin{array}{l}\text { Size } \\
\text { roll }\end{array}$} & \multicolumn{2}{|c|}{$\begin{array}{l}\text { Driving shaft } \\
\text { rev. per min. }\end{array}$} & \multicolumn{2}{|c|}{ Yd. per min. } & \multirow{2}{*}{$\begin{array}{l}\text { Speed } \\
\text { range }\end{array}$} \\
\hline & & Min. & Max. & Min. & Max. & \\
\hline 4 & $16-1 / 2$ & 43 & 129 & 14.5 & 44.5 & $3.0-1$ \\
\hline 5 & $16-1 / 4$ & 70 & 238 & 22.0 & 82.0 & $3.4-1$ \\
\hline 6 & $15-7 / 8$ & 68 & 211 & 22.8 & 76.0 & $3.1-1$ \\
\hline 8 & 15 & 48 & 231 & 15.0 & 71.5 & $4.82-1$ \\
\hline 9 & $16-3 / 4$ & 49 & 173 & 15.4 & 56.5 & $3.5-1$ \\
\hline
\end{tabular}

2. These tests made on one machine, running first seven colors, then eight, show extreme changes in speed sometimes called for.

\begin{tabular}{l|l|c|c|c|c}
\hline & \multirow{3}{*}{ Colors } & \multicolumn{2}{|c|}{$\begin{array}{c}\text { Driving shaft } \\
\text { rev. per min. }\end{array}$} & \multicolumn{2}{c}{ Yd. per min. } \\
\hline & roll & Min. & Max. & Min. & Max. \\
\cline { 2 - 5 } & $15-7 / 8$ & 24.5 & 220 & 8.1 & 72.6 \\
7 & $16-1 / 4$ & 4.2 & 252 & 1.4 & 84.0 \\
8 & $17-1 / 8$ & 25.0 & 188 & 8.4 & $62-1 / 2$ \\
\hline
\end{tabular}

The following tests show speed and watts input on control points provided with electric drive on different sized machines on normal operation.

3. Test on two-color duplex machine, with two print rolls per side, two grays on one side and one on the other, Baker cloth blanket, three drying cans for cloth, two drying cans for one gray and three small drying cans for the other gray.

\begin{tabular}{c|c|c|c|c}
\hline $\begin{array}{c}\text { trol } \\
\text { points }\end{array}$ & $\begin{array}{c}\text { Shaft } \\
\text { rev. per min. }\end{array}$ & $\begin{array}{c}\text { Yd. } \\
\text { per min. }\end{array}$ & $\begin{array}{c}\text { Motor } \\
\text { rev. per min. }\end{array}$ & $\begin{array}{c}\text { Watts } \\
\text { input }\end{array}$ \\
\hline 1 & 43 & 14.5 & 69 & 4950 \\
2 & 56 & 18.8 & 90 & 4620 \\
3 & 63 & 21.1 & 101 & 3850 \\
& & & & \\
4 & 65 & 21.9 & 104 & 4950 \\
5 & 83 & 28.1 & 133 & 5060 \\
6 & 105 & 35.3 & 168 & 6160 \\
7 & & & & \\
8 & 115 & 39.4 & 184 & 8800 \\
& 129 & 43.5 & 206 & 8800 \\
\hline
\end{tabular}

4. Test on five-color machine with drag roll, 31-in. cotton cloth, two grays, baker cloth blanket, three cloth drying cans, two gray drying cans.

\begin{tabular}{c|c|c|c|c}
\hline $\begin{array}{c}\text { Control } \\
\text { points }\end{array}$ & $\begin{array}{c}\text { Shaft } \\
\text { rev. per min. }\end{array}$ & $\begin{array}{c}\text { Yd. } \\
\text { per min. }\end{array}$ & $\begin{array}{c}\text { Motor } \\
\text { rev. per min. }\end{array}$ & $\begin{array}{c}\text { Watts } \\
\text { input }\end{array}$ \\
\cline { 1 - 2 } 1 & 70 & 22 & 112 & 2200 \\
2 & 75 & 25 & 120 & 2640 \\
3 & 74 & 23.4 & 118 & 2530 \\
& & & & \\
4 & 83.5 & 28 & 133 & 3080 \\
5 & 89 & 30 & 142 & 3080 \\
6 & 116 & 40 & 185 & 3190 \\
7 & 147 & 50 & & \\
8 & 147 & 50 & 235 & 6380 \\
9 & 147 & 50 & 235 & 6380 \\
& & & & 6380 \\
10 & 168 & 60 & 269 & 6600 \\
11 & 180 & 63 & 288 & 7700 \\
12 & 238 & 82 & 381 & 8800 \\
\hline
\end{tabular}

5. Test on six-color machine with drag roll printing 27-in. cotton cloth with one gray. and rubber blanket.

\begin{tabular}{c|l|l|c|c}
\hline $\begin{array}{c}\text { Control } \\
\text { points }\end{array}$ & $\begin{array}{c}\text { Shaft } \\
\text { rev. per min. }\end{array}$ & $\begin{array}{c}\text { Yd. } \\
\text { per min. }\end{array}$ & $\begin{array}{c}\text { Motor } \\
\text { rev. per min. }\end{array}$ & $\begin{array}{c}\text { Watts } \\
\text { input }\end{array}$ \\
\cline { 2 - 3 } & 68 & 22.8 & 109 & 3960 \\
2 & 61.5 & 20.3 & 99 & 2860 \\
3 & 68.5 & 23 & 110 & 2750 \\
4 & 76.5 & 25 & 122 & \\
5 & 88 & 29.5 & 141 & 3190 \\
6 & 114 & 38.4 & 183 & 4180 \\
7 & 133 & 44 & & \\
8 & 144 & 48.5 & 213 & 5500 \\
9 & 141 & 47 & 226 & 6160 \\
10 & 160 & 54.5 & 256 & 6600 \\
\hline
\end{tabular}

6. Test on eight-color machine with one gray, rubber blanket, three cloth dry cans, 84 in. by 50 in., two dry cans for gray, and printing 27 -in cotton cloth. 


\begin{tabular}{c|c|c|c|c}
\hline $\begin{array}{c}\text { Control } \\
\text { points }\end{array}$ & $\begin{array}{c}\text { Shaft } \\
\text { rev. per min. }\end{array}$ & $\begin{array}{c}\text { Yd. } \\
\text { per mi } .\end{array}$ & $\begin{array}{c}\text { Motor } \\
\text { rev. per min. }\end{array}$ & $\begin{array}{c}\text { Watts } \\
\text { input }\end{array}$ \\
\cline { 2 - 3 } 1 & 48 & 15 & 77 & 4620 \\
2 & 58.5 & 18.3 & 94 & 4070 \\
3 & 62 & 19.7 & 99 & 3850 \\
4 & & & & \\
5 & 65.5 & 20.5 & 105 & 4070 \\
6 & 87 & 27 & 139 & 4290 \\
7 & 109 & 33.9 & 175 & 4950 \\
8 & 124.5 & 38.8 & 199 & 7920 \\
9 & 139 & 43.3 & 222 & 7920 \\
& 135 & 42 & 213 & 7920 \\
10 & 160 & 50 & & \\
11 & 179 & 56 & 256 & 7920 \\
12 & 231 & 72 & 370 & 8800 \\
\hline
\end{tabular}

7. Test on nine-color machine with one gray, rubber blanket, cloth 36 in. wide.

\begin{tabular}{c|c|c|c|c}
\hline $\begin{array}{c}\text { Control } \\
\text { points }\end{array}$ & $\begin{array}{c}\text { Shaft } \\
\text { rev. per min. }\end{array}$ & $\begin{array}{c}\text { Yd. } \\
\text { per min. }\end{array}$ & $\begin{array}{c}\text { Motor } \\
\text { rev. per min. }\end{array}$ & $\begin{array}{c}\text { Watts } \\
\text { input }\end{array}$ \\
\cline { 2 - 3 } 1 & 49 & 15.4 & 80 & 4620 \\
2 & 68 & 22.8 & 111 & 4950 \\
3 & 65 & 20.7 & 106 & 4730 \\
4 & & & & \\
5 & 70.5 & 22.2 & 116 & 4950 \\
6 & 85 & 27.1 & 139 & 5500 \\
7 & 104.5 & 33.5 & 171 & 6710 \\
8 & 130 & 42.2 & & \\
9 & 157 & 51.2 & 213 & 10100 \\
& 144 & 47 & 236 & 11000 \\
10 & & 49 & & 11000 \\
11 & 152 & 56.5 & 249 & 11000 \\
\hline
\end{tabular}

From the foregoing it may be seen that the load of a printing machine unit is determined by the operating conditions existing in each plant and that no rule can be given to cover it for cases in general. Experience and tests have enabled some plants to fix an approximate rating for the different sizes of machines running their particular line of goods, e.g., a large plant printing silk goods has adopted the following ratings:

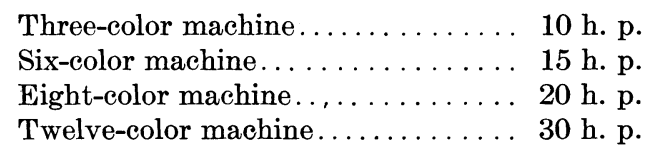

Another large plant printing cotton goods adopted the following:

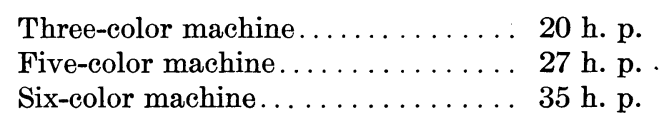

Another specified 50 h. p. for an eight-color machine on cotton goods.

\section{Method OF DRIVING}

The print rolls which are the principal part of the machine are run by one large gear $A$ (Fig. 8) separately mounted and meshing with the print roll pinions $B$. This gear is in turn driven by pinion $C$ mounted on a separate shaft $D$. This is in turn driven by gear, chain or pulley driven from a general power line shaft, separate steam engine or electric motor.
Whenever electric power is available, the line shaft or steam engine methods of drive are usually superseded by the electric motor and control designed to give the required operating speeds.

On account of the wide range of various speeds required for setting, testing and running the cloth, also because of the necessity of frequently running goods at low speeds, and as the machine may run for a considerable time at low speeds during which the motor should be efficient, this is best obtained with a direct-current motor.

There are three systems of electric drive applicable to printing machines, all of which are designed to give the speed changes required for this class of work, viz.:

(1) Direct-current motor with multi-voltage control,

(2) Commutator-type a-c. motor,

(3) Direct-current motor with field and armature control by resistance.

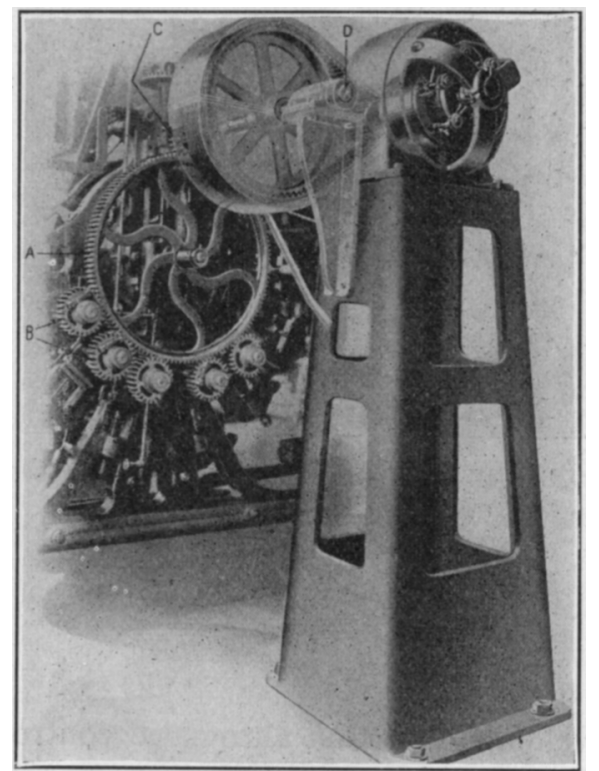

Fig. 8-Drive End of Printing Machine with Standard D-C. Motor and Chain Drive

$A$ Main driving gear for print rolls. $B$ Print roll gears.

$C$ Driving pinion.

$D$ Driving shaft.

Courtesy Rice, Barton \& Fales Machine \& Iron Co., Worcester, Mass.

The first, or multi-voltage system is one which supplies a number of operating voltages for the motor to give the necessary speed changes. The system requires special generating equipment and also additional line wires to supply these voltages. Hand or automatic control is used to throw the motor on to the different lines.

The second, or commutator-type a-c. motor, is the straight series type commutating motor with brush shifting device, the motor being operated from the constant voltage a-c. lines, and the speed changes obtained by shifting the brushes on the commutator.

The third, or direct-current type with field and armature control by resistance, is the standard d-c. motor 
used with external resistance for both field and armature, and manipulated automatically by push buttons or by hand with face plate or drum controller.

The standard direct-current motor has long been successfully applied to this class of work. It meets the requirements of speed changes and runs efficiently at light loads, a condition which often exists in printing.

The particular feature which has lately brought the standard d-c. motor to the fore for this application

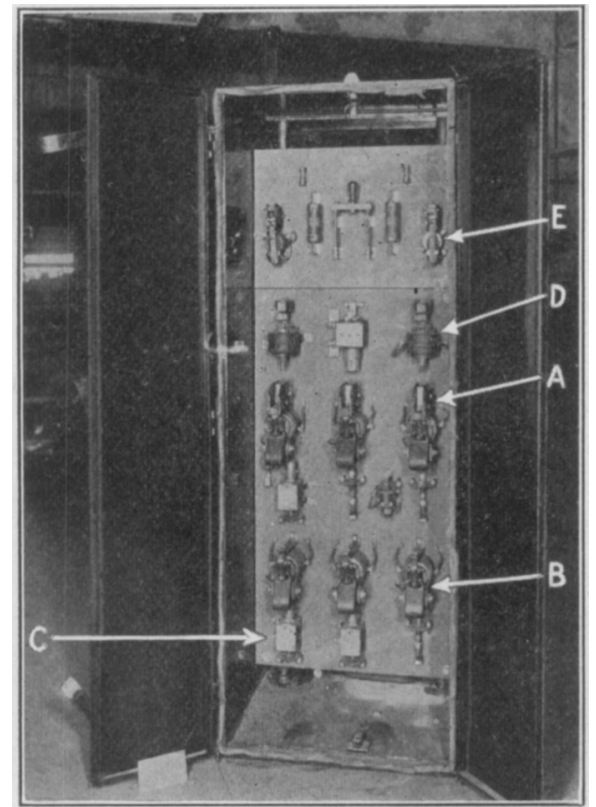

Fig. 9-Automatic Electric Control Panel for D-C. Motor for Printing Machine

$A$ Shunt armature contactor.

$B$ Armature accelerating contactor.

$C$ Armature accelerating relays.

$D$ High torque relay.

$E$ Full field relay.

is the development of the automatic control for this motor. This enables the printer to give his entire attention to the product and to change quickly and adjust speeds from any selected locations.

\section{The CONTROL}

This control consists of a series of magnetic contactors and rheostats, either mounted complete on a panel or with rheostats combined in a single unit and separately mounted.

The speed of the motor is regulated through armature and field control by the use of these contactors and resistances and may be controlled by hand operation of the rheostats, or automatically by the use of push-button stations. The low operating speeds are obtained by the use of resistors, both in series and in shunt with the armature, the field of the motor being at its maximum strength. The higher speeds are obtained by first connecting the armature of the motor directly to the line and then weakening the field.

Assuming that the controller is manipulated by means of push buttons, five usually constitute a com- plete set. These consist of a "start," "stop," "jog" or "inching," "low-speed," and "high-speed" buttons.

The jog or inching button is for the purpose of operating at a low speed when setting the print rolls for correct registration. This would be a speed less than the rated low speed of the motor; $e . g$., if the motor is designed to give 500 to 1500 rev. per min., by field control, the jog button should give a motor speed of 125 rev. per min. if held down long enough for the motor to attain this speed. In setting for registration, however, the button is frequently pushed and released before the motor attains this speed, so that mere starting of the print roll may be accomplished. The machine should run only while the button is held down, and stop when the button is released. This enables the printer to make a rapid setting and prevents waste of cloth.

After the setting of the print rolls, the machine is operated for the normal run from the four remaining buttons.

In starting the machine, the "start" button being depressed momentarily, causes the motor to accelerate automatically to the speed for which the rheostats are set. This speed may be a fraction of or the full speed of the motor depending upon whether the "slow" or the "fast" button is depressed. Either speed is predetermined for the class of goods to be run, the low speed being such as will enable the operator to inspect the quality of printing, which may be one-quarter to one-half the low rated speed of the motor, and the "fast" being the highest speed at which the cloth can be properly printed and dried. The motor continues to run at this speed until changed by depressing another button. If the machine is running full speed, then depressing the "slow" button reduces the speed to that usually required for inspecting, or if running at low speed, then depressing the "fast" button increases the speed to full. Depressing the "stop" button stops the motor when running on any operating speed or during acceleration.

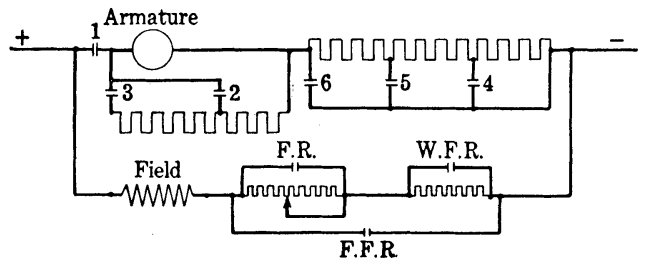

Fig. 10-Control Diagram for D-C. Motor for Printing Machine Drive

Usually several "stop" buttons are connected in series and located one at the front of the printing machine and one at the cloth delivering end of the dryer, and often between these points as may seem advisable so that the motor can be stopped from these points during ordinary inspection, or in case of accident.

$A$ "safe run" button station is sometimes provided near the five-button station for making 
the machine safe during repairs, adjustments, or changing the print rolls.

Dynamic braking is often desirable to bring the machine to a quick stop and can be readily obtained by

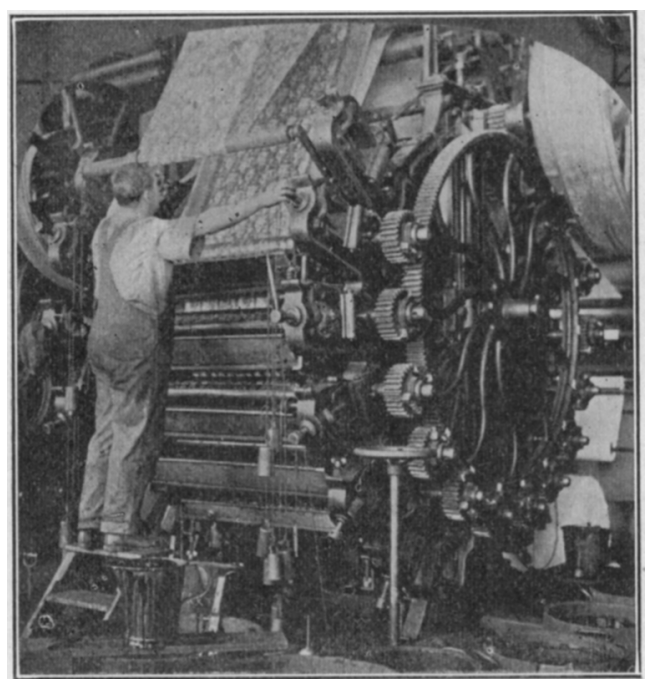

Fig. 11-Twelve-Color Cloth Printing Machine in Operation, Lawrence, Mass.

Tubs containing colors shown in lower foreground. Finished printed cloth shown above operator.

Courtesy National Geographic Society, Washington, D. C.

connecting resistance across the armature cricuit of the motor when the line contactor is open.

Fig. 10 illustrates the scheme of connection which shows the principal operating features of such a control. The starting resistor in the armature circuit of the motor is short-circuited by contactors No. 4, 5,

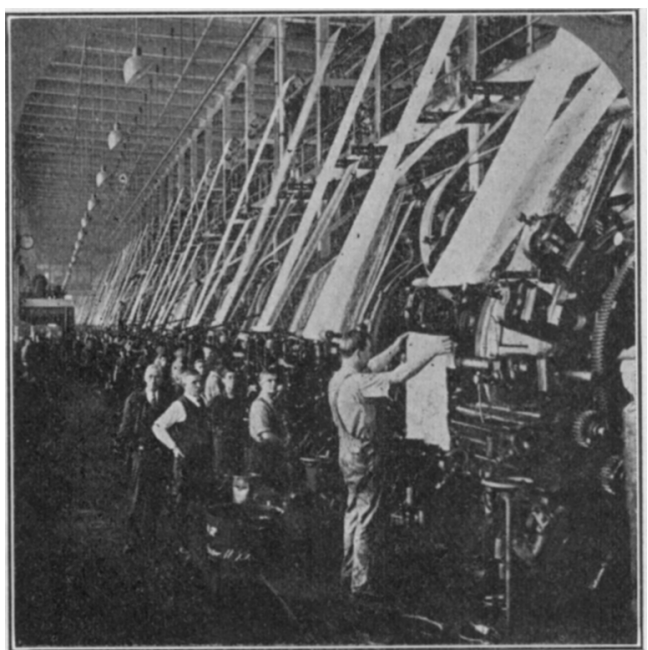

Fig. 12-Battery of 48 Printing Machines at Work, Lawrence, Mass.

Courtesy National Geographic Society, Washington, D. C.

and 6 , the closing of these being controlled automatically by relays which function in proportion to the load on the motor. The other resistance in the armature circuit is used for regulating the speed of the motor and for dynamic braking. The resistor in series with the field winding is used for obtaining the higher operating speeds by reducing the field strength of the motor. This field rheostat is short-circuited by a relay which gradually reduces the field strength during acceleration by alternately opening and closing the shunt to this rheostat. This relay is actuated by a series winding which closes the contact when the current exceeds the fixed value and opens it when the current is reduced to normal.

High starting torque is very desirable in such an application and can be readily obtained by the use of a torque relay.

It is very desirable to have the current in the shunt field reduced below normal while the motor is not running, to prevent heating of the field coils. At the same time normal field current is preferable for dynamic braking. Both can be obtained by the use of a relay.

This paper has been prepared with the assistance of $\mathrm{H}$. D. James, member of the committee on Industrial and Domestic Power.

\section{EFFECTS OF DISTRIBUTED CAPACITY BETWEEN INDUCTANCE COILS AND GROUND}

An inductance coil behaves in an electric circuit primarily as an inductance. The potentials of the different parts of the coil are, however, different from each other and from the potential of the ground. For this reason the coil also behaves to a certain extent as an electric condenser. The effective capacity of an inductance coil depends in general both on the capacities existing between parts of the coil itself, and between parts of the coil and the ground.

On account of the importance in radio communication of capacity effects in inductance coils, careful studies of these effects, have been made at the Bureau of Standards. An interesting result which has been found is that one effect seems to depend primarily on the capacity of the coil to ground. This effect is observed when two condensers in series are connected across the terminals of the inductance coil, and the common terminal of the two condensers is grounded. If the inductance coil possesses capacity to ground, the familiar criterion for resonance in the system, computed from the known values of the capacities of the two condensers, will not obtain.

If the method of measuring the effective capacity is that of resonance adjustment, and if a coil symmetrical as to its two terminals is used, it is found that with the common terminal grounded the capacity of the two condensers in series determined as the product of their capacities divided by their sum, is linearly related to the reciprocal of the sum of their capacities. This relation has been verified both mathematically and experimentally.

The results of this investigation are given in a recent publication of the Bureau, Scientific Paper No. 427, by Gregory Breight. 